\title{
Biomaterials and Their Applications in Dentistry - A Literature Review
}

\author{
Mahesh K.P. ${ }^{1}$, Meenakshi Srinivasa Iyer ${ }^{2}$, Raghavendra Swamy K.N. ${ }^{3}$, Karthikeya Patil ${ }^{4}$, Raghunath N. ${ }^{5}$ \\ 1, 4 Department of Oral Medicine and Radiology, JSS Dental College and Hospital, JSSAHER, Mysore, \\ Karnataka, India. 2, 3 Department of Prosthodontics, Crown and Bridge, JSS Dental College and \\ Hospital, JSSAHER, Mysore, Karnataka, India. ${ }^{5}$ Department of Orthodontics, JSS Dental College, \\ JSS Academy of Higher Education \& Research, Mysore, Karnataka, India.
}

\begin{abstract}
With an estimated 20 million individuals possessing an implanted medical device, biomaterials are now commonly used in medicine and dentistry. Today, biomaterials are widely used in dentistry. Biomaterials are widely used in dentistry. They are divided into four general categories of polymers, ceramics, metals and composites. A variety of dental biomaterials have been developed as clinical needs of dental patients has increased. Newly developed dental biomaterials should be physically stable and biocompatible for their own purposes in oral environment. The extensive use of biomaterials, however, remains a relatively recent concept and dates back to the 1950s. This has contributed to a paradigm shift in the design of biomedical devices over the past 25 years, from being biologically inactive to fully incorporated. By exploring the rationale and clinical demand that have guided both the developments in clinically applied devices and those at the research and development level, this mini review highlights the production and application of biomaterials. Relevant areas of current research activities are addressed and some of the criteria.
\end{abstract}

\section{KEY WORDS}

Biomaterials, Dental, Tissue Engineering, Polymers, Stem Cell Research
Corresponding Author: Dr. Meenakshi S.,

Assistant Professor,

JSS Dental College and Hospital,

S S Nagar, Mysore, Karnataka, India.

E-mail:dr.meenakshis@jssuni.edu.in

DOI: $10.14260 / j e m d s / 2021 / 399$

How to Cite This Article:

Mahesh KP, Iyer MS, Swamy KNR, et al. Biomaterials and their applications in dentistry - a literature review. J Evolution Med Dent Sci 2021;10(26):1940-1947, DOI: 10.14260/jemds/2021/399

Submission 22-02-2021,

Peer Review 02-05-2021,

Acceptance 07-05-2021,

Published 28-06-2021.

Copyright (C) 2021 Mahesh K.P. et al. This is an open access article distributed under Creative Commons Attribution License [Attribution 4.0 International (CC BY 4.0)] 


\section{BACKGROUND}

In recent years, understanding of dental biomaterials has increased multifold, as there is real potential for tissue and organ system biological engineering. In the changing times, the history is redirected in terms of refocusing and introducing fresh and exciting innovations. Biomaterials are material science that has evolved from modern material-structure knowledge. The application of material science to biology is biomaterials. ${ }^{1}$ The response of host cell and tissue towards implant are controlled by biomaterial surface properties and biological combination of prosthetics and tissue-engineering. A widely agreed concept is not established yet, but I would like to suggest, it is body's natural and artificial structural elemental analysis based on the relationship between structure, physicochemical and mechanical properties.

The biggest catalyst for progress came after sequencing the human genome at the end of the last century, despite constant debates and reorientation of the world of biomaterials. There is a conflicting scenario in a twenty to twenty-five-year transformation from conventional synthetic biomaterials to a time where genuinely biological materials are included in the routine choices. Two of the major increasing research areas are dental biomaterials and natural products, indeed exhibit plant-derived products can enhance the physicochemical properties of biomaterials used in dentistry.

This paper attempts to demonstrate the various forms of natural and synthetic products being used as biomaterials in the field of dentistry. The idea is to see the immediate future or the next five-to-ten-year cycle. In this way, the manufacturing of biomaterials (tissue engineering, nano engineering, self-assembly systems); lead to a cutting edge in the dental applications (bonding, composites, curing, cements, and ceramics) and evaluation of the synthetic biomaterials for dental applications. Theoretically, the indicated medicinal and surgical needs are served, any natural or artificial substance can be a biomaterial (Fig 1).

It includes aspects of medicine, biology, chemistry, tissue engineering, and material science. Nonetheless, since last decade, the demand for biocompatible, biodegradable and bioresorbable products has increased significantly. The specifications for biomaterials are non-immunogenicity, biocompatibility, and biodegradability, functionalized with bioactive proteins and chemicals. Biodegradability is a basic property of biomaterials. ${ }^{2}$

"A biomaterial was defined by the National Institutes of Health Consensus Development Conference as "Any substance (other than a drug) or combination of substances of synthetic or natural origin that can be used for any length of time, as a whole or as part of a system that treats, improves or replaces any tissue, organ or body function". ${ }^{3}$ In ancient cultures, the use of biomaterials goes way back. On Egyptian mummies, fake eyes, ears, jaws, and noses were found. ${ }^{4}$

Waxes, glues, and tissues were used by Chinese and Indians in reconstructing damaged or faulty body parts. Over the decades, advances in synthetic materials, surgical procedures, and methods of sterilization have in many ways enabled the use of biomaterials.

Biomaterials can be categorised into four primary material groups, such as, polymers, ceramics (carbons, ceramic lenses and glasses), metals and natural products (both plant and animal products). (Fig 2)

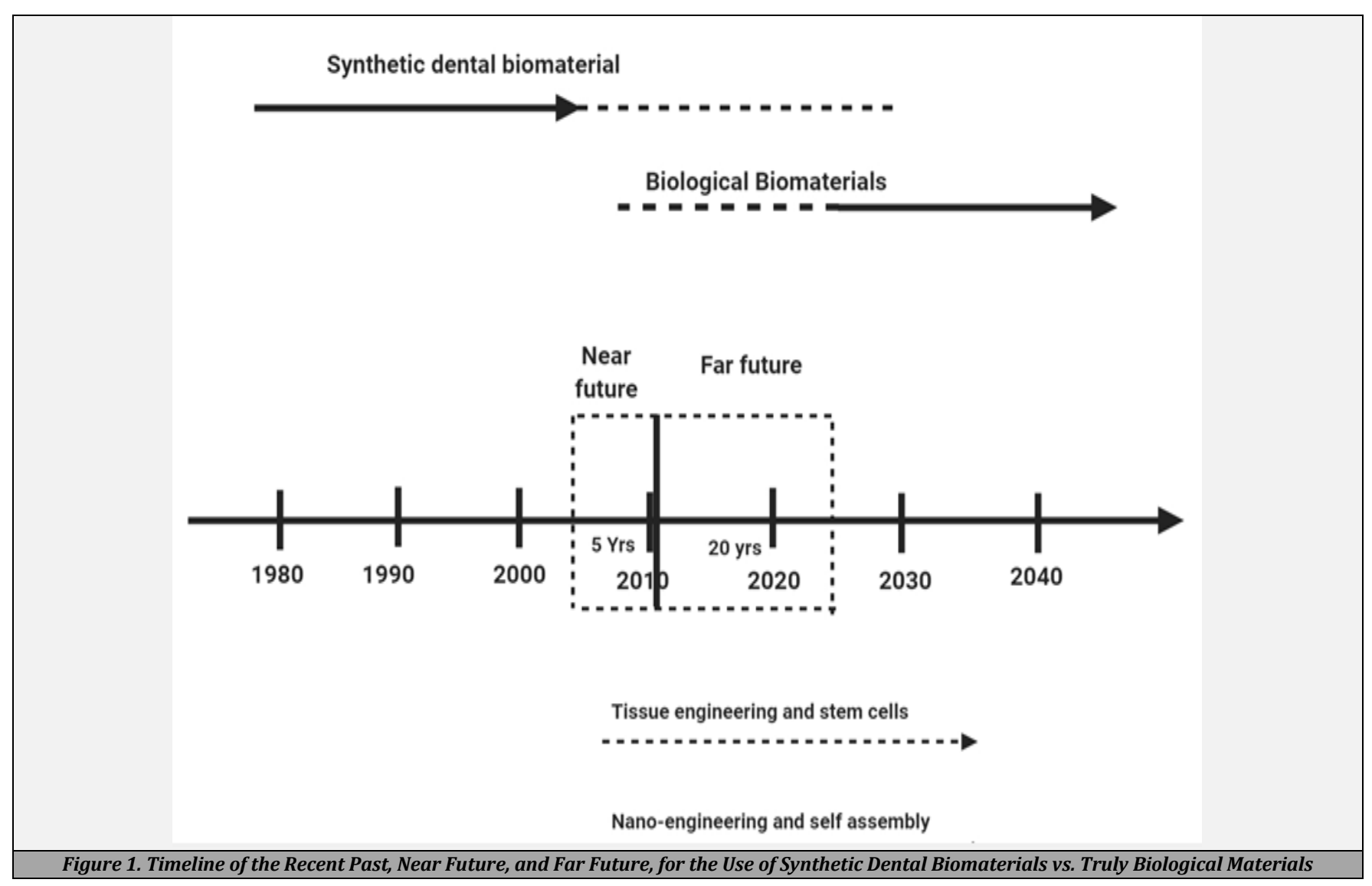




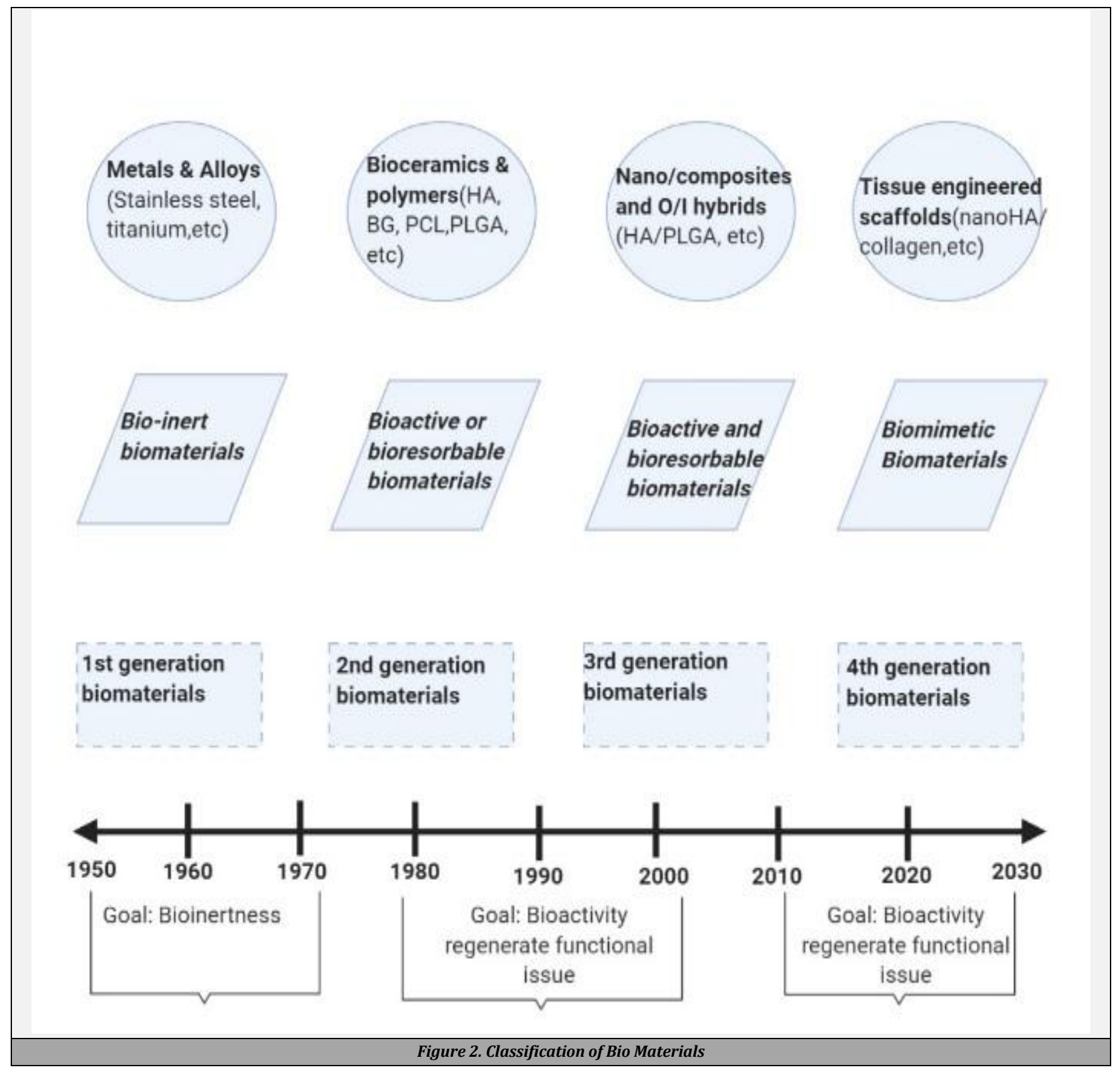

Composite materials consist of two or more distinct material groups and are known to be the fifth biomaterial class. ${ }^{5}$ Metals rarely exist as a single object in nature; thus, are synthesized from their ores, (oxides, sulphides, and carbonates, with an exception of precious metals such as gold and platinum). Metals of natural origin were applied in ancient times as dental materials.

An emerging interest in the natural product has been witnessed as a source of bioactive materials which can be utilized for novel medicine production and treatments, also their use as pharmaceuticals is trending. Natural biomaterials are the biomaterials that have been originated from plant or animal source, and are being considered for use.

The advantage of common insert materials is that they are like materials and normal for body structures. The science of biomimetics (or mirroring nature) is evolving in such a way that it is possible to expose different materials to immunogenicity problems. Their tendency to undergo denaturation or break down at temperatures lower than their liquefying point is another concern explored by these products, essentially by typical polymers. This severely limits the production of inserts in various sizes and shapes. Characteristic products typically are not harmful like that of engineered materials. They can also express explicit protein limiting location. ${ }^{6}$

\section{ADVANCES IN BIOMATERIALS}

\section{Application on Natural Tissues}

Tissue Engineering and Stem Cell Research Currently, approaches towards engineered tissues focus on synthetic scaffolds that are resorbable. Real biological biomaterials result in the regeneration of natural tissue. 


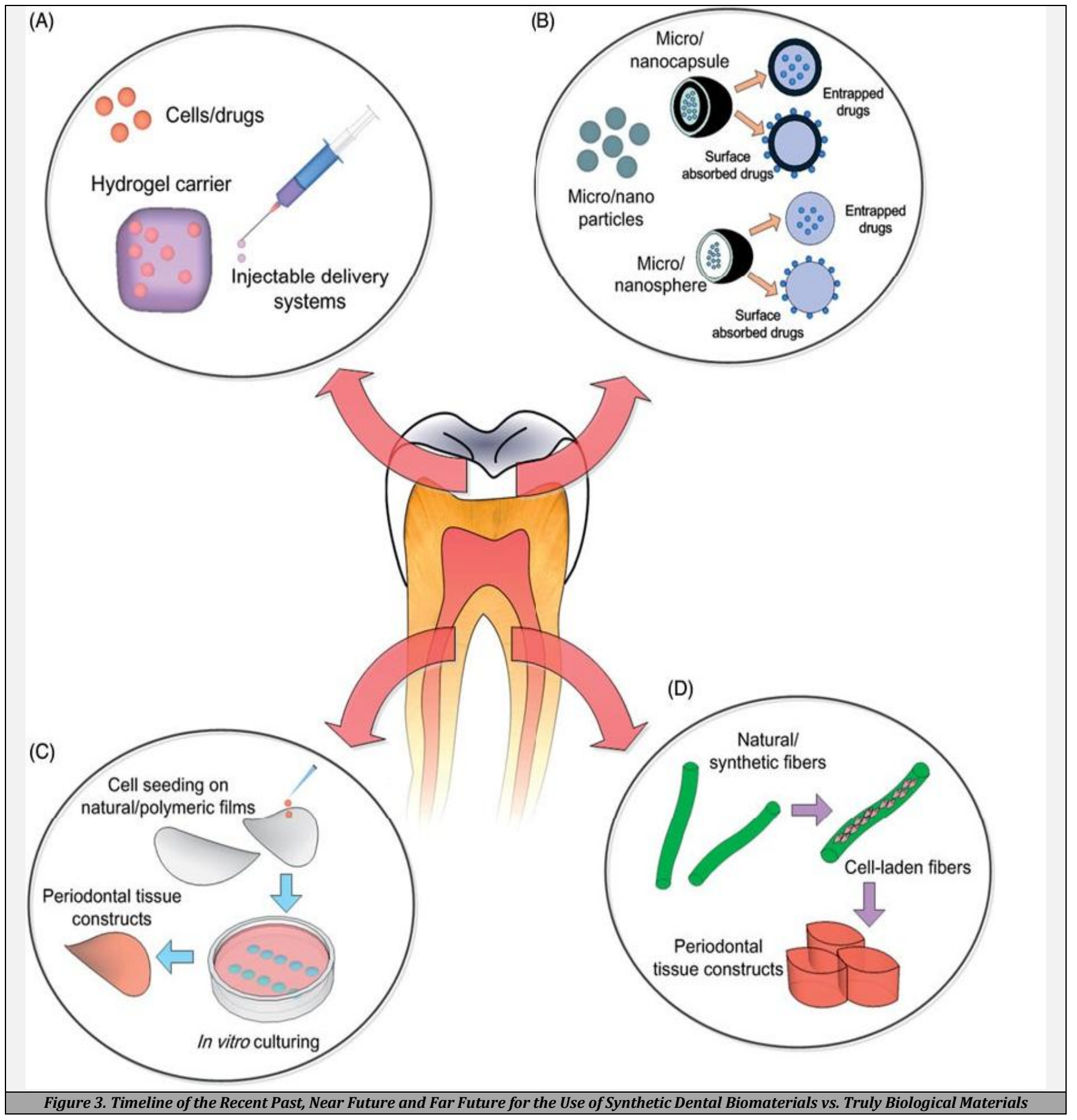

In the orofacial complex, there is great scope for recovery after fracture, augmentation of bone, temporomandibular joint (TMJ) cartilage replacement / reconstruction, pulpal repair, periodontal ligament regeneration, and osseo implant incorporation has recently taken an important role in dentistry. It is widely accepted that the inclusion of biomaterials in regenerative medicine maximizes the positive benefits of cellular therapy thus, reducing weak engraftment, enhancing survival and regulating the transmission of cell / growth factor for cycles. ${ }^{7}$ Three main elements needed for regenerative therapies are: a scaffold in extracellular matrix (maybe synthetic), progenitor or stem cells, and inductive morph-genetic signals. As, easy access and observation is possible in dentistry,

Transplantation of stem cells of dental pulp can restore bone or rebuild teeth, being advantageous than other body parts for tissue engineering. By using stem cells of the patient, histocompatibility problems can be eliminated. In regeneration studies performed in animal models, good support for this potential exists. Scaffolds, cells, and signals have been combined without much elegant control relatively until recently.

There are currently a number of traditional periodontal disease care techniques, these procedures have many deficiencies, such as incompetency to penetrate deep pockets or furcation zones, and strong dependency upon the clinician's expertise. ${ }^{8}$

A new era of biomaterials and engineering is suggested for periodontal regeneration to facilitate greater cell recruitment, regulate cellular activity and regeneration of complex structures and functions of tissues. These working materials can be derived by managing numerous properties such as 
biocompatibility, biodegradability and suitable mechanical properties.

Poly (lactic acid) (PLA), poly (glycolic acid) (PGA), their copolymers (e.g. PLGA) and hydrogel-based polyethylene glycol (PEG) structures are examples of synthetic polymers used for periodontal regeneration; natural polymers (collagen, agarose and gelatin); autologous materials (fibrin) ${ }^{9}$ are also utilized for this purpose (Fig 2).

1. Cell-encapsulating hydrogels / drugs can be injected for reconstruction of periodontal tissue.

2. The form of biodegradable micro / nanoparticles used for the distribution of periodontal pharmaceutical items. Biodegradable micro / nanoparticles are known as micro / nanocapsules and micro / nanospheres, based on the structural organisation. On the surface, the drug molecules are either stuck inside or adsorbed.

3. PDL cell-seeded natural / polymeric films and in vitro cultured for periodontal tissue constructs.

4. Cells are planted on natural / synthetic scaffolds and such scaffold-cell structures are supplied for the treatment of periodontal disease.

\section{PLANT BASED PRODUCTS FOR PERIODONTAL REGENERATION}

Using biocompatible barriers, biomimetic molecules have been suggested as a single or in combination with directed regeneration of tissue or guided regeneration of bone. They are used due to their ability to enhance cell growth and differentiation in periodontal apparatus, mimicking physiological tooth formation, and production of periodontal attachment. ${ }^{10}$ It has been stated that certain plant products derived from medicinal and food plants play an important role in treating periodontal disease, 11,12 facilitating periodontal healing, i.e., Cissus quadrangularis, Carthamus tinctorius and Glycine max (Table 1).

\section{NANO TECHNIQUES OR TECHNOLOGIES}

The range of study for the new biomaterial designing has not only increased, but also the research tools. The pre-treatment (pre-integration) of certain tissues that would usually result from healing / osseointegration could benefit non-biological material surfaces, such as implants. Bioceramics are known by their bioactivity and bioinertness (dental implant alumina) (bioactive [hydroxyapatite, Ca (PO4) 2], Bioglass and bioabsorbable [implant tricalcium phosphate, $\left.\mathrm{Ca}_{3}\left(\mathrm{PO}_{4}\right)_{2}\right)_{1}{ }^{13}$ For current implant systems, this has already been assessed. For applications in biomedical field such as dental restorations, middle ear repair, facial and cranial bone restoring, and filling of bony defects, bio ceramics have been suggested, to name a few. Commercially accessible porous bio ceramics have been documented to be derived from two sources: hydroxyapatite (e.g., pro-osteon) and bone (e.g., Endobon). ${ }^{14}$

\section{PLANT PRODUCT BASED TITANIUM IMPLANT COATINGS}

Titanium (Ti) or its alloys are the standardised materials for orthopaedic and dental implant metals because they are inert and provide bio-devices having high strength, stress resistance and relatively low elastic properties. 15,16

Titanium dental implant osseointegration is 'a procedure in which clinically asymptomatic rigid fixation of alloplastic material during functional loading is accomplished and preserved in the bone'.17 As well as the cornerstone of clinical success, osseointegration is the final aim to be pursued, enabling the device's long-term reliability and functionality. A biomaterial implantation typically induces a reaction identifying it as an external entity, usually manifested as the introduction of phagocytes and fibrous capsule formation in the tissue of the peri-implant area. ${ }^{18,19}$ Titanium is fibrousintegrated and not osseointegrated in this state, particularly affecting implant output and causing complications which may eventually conclude towards implant loosening. ${ }^{20}$

In an effort to improve the overall treatment process by achieving faster osseointegration, the bio mimetic agents used, represents a developing area of research in implant dentistry. In order to cover the surface of the titanium implant, bioactive agents can be added, like biocompatible ceramics, bioactive proteins, peptides, ions and polymers, ${ }^{21,22}$ as important molecules for promoting regeneration of bone through Ti. Some of the protein / peptide coatings used to enhance their biocompatibility are collagen-I, RGD-peptide, and chondroitin sulfate.23,24 Moreover, a limited number of studies have documented pectin like carbohydrate of plant and titanium implant coatings (Table 1 ).

\begin{tabular}{|c|c|c|c|}
\hline Plant Products & Biomaterials & Applications & References \\
\hline Malus domestica L. & Titanium implant coating & $\begin{array}{c}\text { Dental } \\
\text { implantology }\end{array}$ & $\begin{array}{c}\text { In vitro }{ }^{24} \\
\text { In vivo (rats) }\end{array}$ \\
\hline $\begin{array}{c}\text { Cissus } \\
\text { quadrangularis L. }\end{array}$ & $\begin{array}{l}\text { Periodontal filler in } \\
\text { association with } \\
\text { hydroxyapatite }\end{array}$ & $\begin{array}{l}\text { Periodontal } \\
\text { regeneration }\end{array}$ & Clinical trial ${ }^{26}$ \\
\hline $\begin{array}{l}\text { Carthamus } \\
\text { tinctorius L }\end{array}$ & $\begin{array}{c}\text { Periodontal filler in } \\
\text { association with collagen } \\
\text { sponge } \\
\text { Periodontal filler in } \\
\text { association with polylactide } \\
\text { glycolic acid } \\
\text { bioresorbable barrier }\end{array}$ & $\begin{array}{l}\text { Periodontal } \\
\text { regeneration } \\
\text { Periodontal } \\
\text { regeneration }\end{array}$ & $\begin{array}{c}\text { In vivo } \\
\text { (beagle dogs) } \\
\text { In vivo } \\
\text { (beagle dogs) }{ }^{27}\end{array}$ \\
\hline Glycine max L. & bioresorbable barrier & $\begin{array}{l}\text { Periodontal } \\
\text { regeneration }\end{array}$ & $\begin{array}{c}\text { In vivo } \\
\text { (beagle dogs) }\end{array}$ \\
\hline Imp & ment of Innovative $I$ & $\begin{array}{l}\text { r the Develo } \\
\text { tal Biomater }\end{array}$ & ment and \\
\hline
\end{tabular}

\section{PECTINS}

Pectins are broad and complicated polysaccharide found among contiguous plant cells in the primary cell wall and middle lamella. They are the main components of plant cell wall matrix, along with hemicellulose molecules, inside which microfibrils of cellulose create a rigid lamellar network worthy of undergoing both osmotic stress and mechanical stress.

They are used extensively on industrial scale. The emulsifying behaviour is especially noteworthy, as the hydrocolloidal gel-forming properties of pectin are widely utilised in the food industry. ${ }^{28}$ The gel capacity of pectin is by several 
negatively charged units of sugar that are vulnerable to binding $\mathrm{Ca}+$ cations (containing $\mathrm{COO}$ groups). Some traits are similar for all polysaccharides utilized for this purpose with structural features depending upon the plant tissues and species. The two main structures can be classified such as smooth and hairy (ramified), where, smooth consists of $\alpha-1,4$ linked D-galacturonic acid residues, in which some are esterified with methanol on the carboxyl group yielding either a high-methyl or low-methyl homogalacturonan chain.

This pectin-cross linked calcium contributes to substantial hydration. ${ }^{29-32}$ The probability of obtaining an in situ biocompatible gelling system for bone tissue engineering,33-35 injectable cell delivery system ${ }^{26}$ and drug delivery system, ${ }^{36,37}$ pectin gelling properties have attracted increasing interest from scientific audiences. Pectin with (a) galacturonic acid and (b) methyl esterified homo galacturonan. ${ }^{38,39}$

Despite being the standard for replacement of bone, alternatives for autologous bone grafting were suggested due to restricted supply of bone graft, morbidity of the patient, and the possibility of allografts related transmittable diseases. A novel biodegradable biomaterial can be obtained by defatted soybean curd processed through simple thermosetting to enhance regeneration of tissue. The known immunosuppressive activity of isoflavones ${ }^{40}$ could counterbalance the result shown by the xenogenetic proteins of soybean.

Recently, Santin and his colleagues reported that granules of biomaterials obtained from soybean lead to the reduction in the activity of monocytes / macrophages and osteoclasts, whereas in vitro differentiation of osteoblasts was induced. ${ }^{41}$ An in vivo rabbit study found that after 8 weeks, the introduction of granules of soybean helped in the repair of bone from those obtained by healing of an untreated defect. ${ }^{42}$ On distal femoral canal (constituting of trabecular bone being a site for bone remodelling study), a critical size defect was performed by the authors. Trabecular bones were identified on the sites where biomaterials based on soybean was utilised, also well-organised maturing trabecular was to be replaced by lamellar bone. This reported study showed the potential of the granules of soybean for regeneration of bones: their intrinsic bioactivity, together with their preparation processes, making them suitable candidates for bone fillers for clinical application.

\section{Synthetic Dental Biomaterials}

Clearly, the major researches since the last decade have been focused on bonding systems, composites, and ceramics.

\section{BONDING SYSTEM}

Since acid etching was introduced, bonding devices have been in continuous production in dental sciences for fifty-five years. Although the aim is to shift towards easier and predictable bonding results, enamel and dentin bonding systems can vanish someday. Up to this point, we have overlooked the fact that other substrates, such as amalgam and ceramic, require bonding. Standard patterns for dentin do not perform as well in such situations. It requires changed bonding systems; this is likely to continue to be true. 43,44

\section{COMPOSITES}

Their future is much more optimistic for a variety of reasons, despite the past related with the production of composites of dentistry and its influential role today. In the short term, nonshrink designs will enter the market, addressing some of the obstacles associated to pressures of the premature bonding device. 45 It would also decrease the internal porosity that could have led to greater water absorption than desired. Not all nanofillers are similar, varietal nanofillers have also been seen.

Sol-gel technology is being used for producing small nanospheres called as nanomers. ${ }^{46}$ these may be coalesced into nanoclusters, and for composite formulations, these may become filler particles. In a positive perspective, we still have to recognise the potential benefits of true nanoscale phases in new composite formulations.

\section{DENTAL BONE GRAFT}

In surgery the use of grafts derived from raw, ceramic, composite or polymeric material is substituted in the case of damaged teeth. As a scaffold and filler to promote bone growth and wound healing, bone graft is a tremendous application in dental implant surgery. Bone grafts are extremely biocompatible and biodegradable, avoiding any antigenantibody response from occurring. The reasons for the growth in demand for dental bone graft and other biomaterials are the growing prevalence of dental deformities, outstanding dental reforms around the world and pioneering technologies embraced by major players to include a variety of products relevant to dental surgery. ${ }^{47}$

Because of its abundance in large amounts from bovine and coral supplies, xenograft is gaining prominence. It is used as a calcium matrix in oral surgery. In conjunction with growth factors such as TGF-beta, BMP-4, BMP-2 etc., synthetic materials such as ceramic, hydroxyapatite and calcium phosphate are used to promote jawbone healing by inducing osteoblast differentiation.

\section{OUTCOMES OF SYNTHETIC AND BIOLOGICAL BIOMATERIALS}

Stepping back from the shimmer of innovations involved in modern biomaterial processing, manufacturing, and science, another significant main topic is still being addressed. ${ }^{48}$ The biocompatibility of biomaterials on a truly empirical basis has never been studied. Most tests have been crude screening procedures. Longevity, as stated by the following, ${ }^{49}$ must be described in relative and not absolute terms. There are many potential factors for any treatment that affect outcomes, including the clinician and the patient, and many possible modes of failure. A minor malfunction does not require repair or replacement. Longevity is the average survivability for a pool of restorations taking into account all possible outcomes. 


\section{CONCLUSIONS}

To have longer service lifetimes, newer biomaterials should become even more damage tolerant. For the same cause, one might argue that a safer option for the treatment would be real biological substitutes (tissue engineered or cloned teeth). This claim, however, suggests that the dental patient has ample tissue, natural healing processes, and good health. All of these shortcomings are reasons why synthetic biomaterials can still be used for a long time to come. The science of materials is based on many foundational sciences, has broad implications, and is mostly dedicated to solid materials. It reflects on the relation between the arrangement of atoms and molecules and the behaviour of a substance in various environments.

Plant-derived products are a novel and interesting candidate for biomaterial applications, including dental research fields. As an alternative to pharmaceuticals and animal-derived compounds, nutraceuticals and phytochemicals can be seen as promising aids in improving biomaterial bioactivity.

Using plant products should not raise ethical questions due to their botanical origin. Most of them are low immunogenic and, at low concentrations, not toxic on their own, though still bioactive. They are usually readily available and economical. Some extracts and compounds, on the other hand, are difficult to obtain, requiring long and complex extraction protocols, chemical characterization and isolation, often with a low yield. It remains a challenge in some cases to isolate a single compound in significant amounts. It is obvious that there is a general lack of scientific research in this area, which could be corrected in the coming decades, since both biomaterials and plant-based compounds are emerging areas of research.

The benefits and limits of these dental materials should be assessed before using them clinically, based on the principles and knowledge of material science. A new range of therapy strategies for dental applications has been provided by an increased study on the use of PMFs. Although most PMFs are not regularly used clinically, their use has demonstrated improvement of dental material's biomechanical properties, which can lead to new treatment alternatives for patients in future. It is still an expanding universe, but one that presents an approach that is necessary for an understanding of material behaviour and the creation of new ones. The issue for today is 'how do biomaterials paint the future?'.

Financial or other competing interests: None.

Disclosure forms provided by the authors are available with the full text of this article at jemds.com.

\section{REFERENCES}

[1] Avila G, Misch K, Galindo-Moreno P, et al. Implant surface treatment using biomimetic agents. Implant Dent 2009;18(1):17-26.

[2] Cao Y, Wang B. Biodegradation of silk biomaterials. Int J Mol Sci 2009;10(4):1514-24.

[3] Boretos JW. Contemporary biomaterials: material and host response, clinical applications, new technology and legal aspects. Noyes Pubns 1984.

[4] Varoni EM, Iriti M, Rimondini L. Plant products for innovative biomaterials in dentistry. Coatings
2012;2(3):179-94.

[5] Ratner BD, Hoffman AS, Schoen FJ, et al. Biomaterials science: an introduction to materials in medicine. $2^{\text {nd }}$ edn. Amsterdam, Boston: Elsevier Academic Press 2004: p. 864.

[6] Schindhelm K, Milthorpe BK. An overview of biomaterials. Australas Phys Eng Sci Med 2003;9(1):29-32. http://www.pubmedcentral.nih.gov/articlerender.fcgi?a rtid=3975359\&tool=pmcentrez\&rendertype $=$ abstract

[7] Chen FM, Sun HH, Lu H, et al. Stem cell-delivery therapeutics for periodontal tissue regeneration. Biomaterials 2012;33(27):6320-44.

[8] Herrera D, Matesanz P, Bascones-Martínez A, et al. Local and systemic antimicrobial therapy in periodontics. J Evid Based Dent Pract 2012;12(Suppl 3):50-60.

[9] Maeda H, Fujii S, Tomokiyo A, et al. Periodontal tissue engineering: defining the triad. Int J Oral Maxillofac Implants 2013;28(6):e461-71.

[10] Beutner R, Michael J, Schwenzer B, et al. Biological nanofunctionalization of titanium - based biomaterial surfaces: a flexible toolbox. J R Soc Interface 2010;7:S93-S105.

[11] Anuj SK, Mishra JN, Behera BR, et al. A plant (Cissus quadrangularis) with various ethnopharmacological action: a review. J Pharm Res 2011;4(6):1887-90.

[12] Deka DK, Lahon LC, Saikia J, et al. Effect of cissus quadrangularis in accelerating healing process of experimentally fractured radius-ulna of dog: a preliminary study. Indian Journal of Pharmacology 1994;26(1):44-5.

[13] Marshall GW, Habelitz S, Gallagher R, et al. Nanomechanical properties of hydrated carious human dentin. J Dent Res 2001;80(8):1768-71.

[14] Pardeike J, Hommoss A, Müller RH. Lipid nanoparticles (SLN, NLC) in cosmetic and pharmaceutical dermal products. Int J Pharm 2009;366(1-2):170-84.

[15] Brunski JB. In vivo bone response to biomechanical loading at the bone/dental-implant interface. Adv Dent Res 1999;13:99-119.

[16] Wennerberg A, Albrektsson T. Effects of titanium surface topography on bone integration: a systematic review. Clin Oral Implants Res 2009;20(Suppl 4):S172-84.

[17] Albrektsson T, Brunski J, Wennerberg A. A requiem for the periodontal ligament revisited. Int J Prosthodont 2009;22(2):120-2.

[18] Clarke SA, Revell PA. Integrin expression at the bone/biomaterial interface. J Biomed Mater Res 2001;57(1):84-91.

[19] Kellar RS, Kleinert LB, Williams SK. Characterization of angiogenesis and inflammation surrounding ePTFE implanted on the epicardium. J Biomed Mater Res 2002;61(2):226-33.

[20] Roberts WE. Bone tissue interface. J Dent Educ 1988;52(12): 804-9.

[21] Avila G, Misch K, Galindo-Moreno P, et al. Implant surface treatment using biomimetic agents. Implant Dent 2009;18(1):17-26.

[22] Kokkonen H, Cassinelli C, Verhoef R, et al. Differentiation of osteoblasts on pectin-coated titanium. Biomacromolecules 2008;9(9):2369-76.

[23] Le Guéhennec L, Soueidan A, Layrolle P, et al. Surface treatments of titanium dental implants for rapid osseointegration. Dent Mater 2007;23(7):844-54. 
[24] Jain A, Dixit, J, Prakash D. Modulatory effects of cissus quadrangularis on periodontal regeneration by bovinederived hydroxyapatite in intrabony defects: exploratory clinical trial. J Int Acad Periodontol 2008;10(2):59-65.

[25] Kokkonen H, Niiranen H, Schols HA, et al. Pectin-coated titanium implants are well-tolerated in vivo. J Biomed Mater Res A 2010;93(4):1404-9.

[26] Kim HY, Kim CS, Jhon GJ, et al. The effect of safflower seed extract on periodontal healing of 1-wall intrabony defects in beagle dogs. J Periodontol 2002;73(12):1457-66.

[27] Song WS, Kim CS, Choi SH, et al. The effects of a bioabsorbable barrier membrane containing safflower seed extracts on periodontal healing of 1 - wall intrabony defects in beagle dogs. J Periodontol 2005;76(1):22-33.

[28] Yapo BM. Pineapple and banana pectins comprise fewer homogalacturonan building blocks with a smaller degree of polymerization as compared with yellow passion fruit and lemon pectins: implication for gelling properties. Biomacromolecules 2009;10(4):717-21.

[29] Redondo-Nevado J, Moyano E, Medina-Escobar N, et al. A fruit-specific and developmentally regulated endopolygalacturonase gene from strawberry (Fragaria $\times$ ananassa cv. Chandler). J Exp Bot 2001;52(362):1941-5.

[30] Vincken JP, Schols HA, Oomen RJFJ, et al. If homogalacturonan were a side chain of rhamnogalacturonan I. Implications for cell wall architecture. Plant Physiol 2003;132(4):1781-9.

[31] Bonnin E, Dolo E, Le Goff A, et al. Characterisation of pectin subunits released by an optimised combination of enzymes. Carbohydr Res 2002;337(18):1687-96.

[32] Liu L, Won YJ, Cooke PH, et al. Pectin/poly (lactide-coglycolide) composite matrices for biomedical applications. Biomaterials 2004;25(16):3201-10.

[33] Munarin F, Guerreiro SG, Grellier MA, et al. Pectin-based injectable biomaterials for bone tissue engineering. Biomacromolecules 2011;12(3):568-77.

[34] Munarin F, Giuliano L, Bozzini S, et al. Mineral phase deposition on pectin microspheres. Mat Sci Eng C 2010;30(3):491-6.

[35] Munarin F, Petrini P, Tanzi MC, et al. Biofunctional chemically modified pectin for cell delivery. Soft Matter 2012;8(17):4731-9.

[36] Munarin F, Petrini P, Farè S, et al. Structural properties of polysaccharide-based microcapsules for soft tissue regeneration. J Mater Sci Mater Med 2010;21(1):365-75.

[37] Ishii T, Matsunaga T. Pectic polysaccharide rhamnogalacturonan II is covalently linked to homogalacturonan. Phytochemistry 2001;57(6):969-74.

[38] Yapo BM. Pectic substances: from simple pectic polysaccharides to complex pectins- a new hypothetical model. Carbohyd Polym 2011;86(2):373-85.

[39] Mohnen D. Pectin structure and biosynthesis. Curr Opin Plant Biol 2008;11(3):266-77.

[40] Friedman M, Brandon DL. Nutritional and health benefits of soy proteins. J Agric Food Chem 2001;49(3):1069-86.

[41] Santin M, Morris C, Standen G, et al. A new class of bioactive and biodegradable soybean-based bone fillers. Biomacromolecules 2007;8(9):2706-11.

[42] Merolli A, Nicolais L, Ambrosio L, et al. A degradable soybean-based biomaterial used effectively as a bone filler in vivo in a rabbit. Biomed Mater 2010;5(1):15008.

[43] Salzmann JA. Craig's Restorative dental materials. Vol. 71. 14th edn. Elsevier Inc 1977: p. 228.

[44] Marshall GW, Habelitz S, Gallagher R, et al. Nanomechanical properties of hydrated carious human dentin. J Dent Res 2001;80(8):1768-71.

[45] Littler D, Tynan C. Where are we and where are we going? Eur J Mark 2005;39(3/4):261-71.

[46] Pardeike J, Hommoss A, Müller RH. Lipid nanoparticles (SLN, NLC) in cosmetic and pharmaceutical dermal products. Int J Pharm 2009;366(1-2):170-84.

[47] Brydone AS, Meek D, MacLaine S. Bone grafting, orthopaedic biomaterials and the clinical need for bone engineering. Proc Inst Mech Eng Part $\mathrm{H}$ 2010;224(12):1329-43.

[48] Kregiel D. Advances in biofilm control for food and beverage industry using organo-silane technology: a review. Food Control 2014;40(1):32-40.

[49] Ige 00, Umoru LE, Aribo S. Natural products: a minefield of biomaterials. International Scholarly Research Materials Science 2012;2012:983062. 